\title{
IL-10 Is a Key Cytokine in Psoriasis Proof of Principle by IL-10 Therapy: A New Therapeutic Approach
}

\author{
Khusru Asadullah, ${ }^{\star}$ Wolfram Sterry, ${ }^{*}$ Katja Stephanek, ${ }^{*}$ Dominik Jasulaitis, ${ }^{\ddagger}$ Mattias Leupold, ${ }^{*}$ Heike Audring, ${ }^{\star}$ \\ Hans-Dieter Volk, ${ }^{\ddagger}$ and Wolf-Dietrich Döcke ${ }^{\ddagger}$ \\ *Department of Dermatology and ${ }^{\ddagger}$ Institute of Medical Immunology, University Hospital Charité, Berlin Humboldt University, D-10098 \\ Berlin, Germany
}

\begin{abstract}
Overexpression of proinflammatory, type 1 cytokines has been demonstrated in psoriasis and is believed to be of pathophysiological importance. IL-10 is a type 2 cytokine with major impact on immunoregulation, since it inhibits type 1/proinflammatory cytokine formation. Therefore, we investigated its role in psoriasis. We found a relative deficiency in cutaneous IL-10 mRNA expression compared with other inflammatory dermatoses. Interestingly, patients during established antipsoriatic therapy showed higher IL-10 mRNA expression of peripheral blood mononuclear cells than patients before therapy. This suggested that IL-10 may have antipsoriatic capacity. Therefore, we performed a phase 2 pilot trial with subcutaneous IL-10 administration $(8 \mu \mathrm{g} / \mathrm{kg} / \mathrm{d})$ over $24 \mathrm{~d}$ in three patients. Clinical efficiency measured by objective and subjective parameters was found. Immunosuppressive effects (depressed monocytic HLA-DR expression, TNF- $\alpha$ and IL-12 secretion capacity, IL-12 plasma levels, and responsiveness to recall antigens) as well as a shift toward a type 2 cytokine pattern (increasing proportion of IL-4, IL-5, and IL-10 producing $\mathrm{T}$ cells, selective increase in IgE serum levels) were observed. Remarkably, IL-10 administration also enhanced the intracutaneous IL-10 mRNA expression. Our investigations demonstrate the major importance of IL-10 in psoriasis and show that IL-10 administration represents a new therapeutic approach. This is the first report on IL-10 therapy for cutaneous disorders. (J. Clin. Invest. 1998. 101:783794.) Key words: psoriasis • cytokines • interleukin $10 \cdot \mathrm{T}$ cells $\bullet$ monocytes
\end{abstract}

\section{Introduction}

Psoriasis is a common cutaneous disorder characterized by inflammation and abnormal epidermal proliferation with a prevalence of $2-3 \%$ in the general population (1). Several observations indicate that $\mathrm{T}$ cells and cytokines (2-8) are of major importance in the pathogenesis of this chronic skin disease.

Address correspondence to Khusru Asadullah, Department of Dermatology, University Hospital Charité, Berlin Humboldt University, D-10098 Berlin, Germany. Phone: 49-30-2802-2923; FAX: 49-302802-2723; E-mail: asadullah@rz.charite.hu-berlin.de

Received for publication 12 August 1997 and accepted in revised form 5 December 1997.

J. Clin. Invest.

(C) The American Society for Clinical Investigation, Inc. 0021-9738/98/02/0783/12 \$2.00

Volume 101, Number 4, February 1998, 783-794

http://www.jci.org
These observations are supported by the beneficial effects of systemic administration of immunosuppressive drugs like cyclosporin A (9), FK506 (10), and fumaric acid esters (11-13), known to act on T cells and to influence the cytokine pattern.

According to the predominant expression of IL-2 and IFN- $\gamma$ and the lack of IL-4 in skin lesions, psoriasis is believed to be characterized by a type 1 cytokine pattern $(4,5,14)$. Moreover, the involvement of other proinflammatory cytokines like IL-1, IL-6, IL-8, and TNF- $\alpha$ has been demonstrated (15-17).

In contrast to proinflammatory cytokines there is only limited knowledge regarding the role of antiinflammatory cytokines in psoriasis. Remarkably, there is rising evidence that a relative IL-1 receptor antagonist deficiency could be of major importance (18). IL-10, another antiinflammatory cytokine, is a potent inductor of IL-1 receptor antagonist (19), suggesting low or absent IL-10 expression in psoriasis. However, conflicting data have been published. Whereas IL-10 mRNA was detected rarely or not at all by some authors $(4,5)$, overexpression has been reported by others $(16,20)$. This may partly result from different PCR techniques used. Moreover, there is no information available regarding the IL-10 expression by psoriatic PBMC, although it is established that these cells may infiltrate into the skin and are involved in the pathogenesis of the disease $(6,21)$.

IL-10 has great impact on immunoregulation. It promotes the development of a type 2 cytokine pattern by inhibiting the IFN- $\gamma$ production of $\mathrm{T}$ lymphocytes and natural killer cells particularly via the suppression of IL-12 synthesis in accessory cells (22). Moreover, it suppresses proinflammatory cytokine production and antigen-presenting capacity of monocytes/ macrophages and dendritic cells $(23,24)$. Interestingly, intravenous injection of IL-10 was shown to inhibit proinflammatory cytokine production and was well tolerated in a single dose up to $25 \mu \mathrm{g} / \mathrm{kg}$ in healthy volunteers (25). Moreover, multiple intravenous administration in patients with Crohn's disease, another type 1 disease (14), showed beneficial effects along with a good local and systemic tolerance (26). Therefore, beneficial effects of IL-10 therapy in psoriasis also may be expected.

Using a competitive quantitative RT-PCR technique, here we demonstrate low cutaneous IL-10 mRNA expression in psoriasis compared with other inflammatory dermatoses. Moreover, established antipsoriatic treatment protocols are shown to be associated with enhanced IL-10 mRNA expression in PBMC. Since this suggested that IL-10 induction may have antipsoriatic activity, we started a pilot trial and report here on the first administration of IL-10 in psoriasis. Objectives of the study in three psoriatic patients were to assess safety aspects as well as effects on disease activity and related immunological parameters. Our results show that therapeutic IL-10 administration as well as selective induction of endogenous IL-10 formation may be useful, new therapeutic approaches in psoriasis. 


\section{Methods}

Noninterventional studies. For comparison of cutaneous IL-10 mRNA expression in psoriasis with that of other inflammatory dermatoses, skin punch biopsies $(4-8 \mathrm{~mm})$ were obtained from adult patients with psoriasis $(n=7)$, cutaneous T cell lymphoma (mycosis fungoides; $n=$ 9 ), and atopic eczema $(n=5)$. In eight patients (two mycosis fungoides, three psoriasis, three atopic dermatitis), an additional biopsy was obtained from uninvolved skin.

To investigate the monocytic IL-10 secretion capacity, endotoxin stimulation was done in whole blood cultures from psoriatic patients $(n=14)$ as well as from currently untreated patients with atopic dermatitis $(n=15)$, cutaneous T cell lymphoma $(n=6)$, and from 10 healthy controls.

The effect of conventional psoriasis treatment (UVB or bathPUVA exposition and topical administration of dithranol and calcipotriol) on IL-10 and TNF- $\alpha$ mRNA expression in PBMC was assessed in venous blood samples, obtained from psoriatic patients before $(n=6)$ and during the first week of therapy $(n=7)$ as well as from healthy donors $(n=12)$.

IL-10 administration protocol. Three otherwise healthy, male patients with chronic plaque psoriasis (age 34, 43, and $53 \mathrm{yr}$ ) were chosen for treatment with IL-10. There was no systemic antipsoriatic treatment, including any phototherapy, during $8 \mathrm{wk}$ preceding the study and no treatment with any standard topical therapy for psoriasis other than with bland emollients during $3 \mathrm{wk}$ preceding the study. Moreover, the patients had no clinical evidence for infection during $3 \mathrm{wk}$ before the study, no anti-ds-DNA antibodies, and no history of cancer. Patients received subcutaneous administrations of recombinant human IL-10 (SCH 52000; kindly provided by Essex Pharma, Munich, Germany) over a period of $24 \mathrm{~d}$ in a daily dosage of $8 \mu \mathrm{g} / \mathrm{kg}$ body wt. In two patients (patients F and G), IL-10 was injected subcutaneously directly under psoriatic plaques and vehicle alone was injected under a control plaque symmetrically localized on the other body side. In the third patient, IL-10 was injected in nonlesional, subcutaneous tissue (patient B).

The study was approved by the Institutional Review Board of the Medical Faculty, and written informed consent was obtained from all patients.

Clinical and immunological investigations in IL-10-treated patients. In IL-10-treated patients, daily clinical examination was performed over a 28-d period. Patients were interviewed regarding side effects and the pruritus was scored. Efficacy was assessed from day 1 (before therapy) up to $4 \mathrm{~d}$ after the end of therapy (day 28) by the psoriasis area and severity index (PASI) ${ }^{1}(27)$, photo documentation, and $20 \mathrm{mHz}$ ultrasound. Three different plaques (including the site of IL-10 and vehicle administration) were monitored in detail in each patient. $20 \mathrm{mHz}$ ultrasound shows an echopoor band in psoriasis, representing both epidermal acanthosis and the infiltrate in the upper dermis, which can be measured exactly (28; see also Fig. 7). Reduction of the echopoor band was expressed as proportional change in comparison to baseline values.

Before (day -6), during (day 18), and $4 \mathrm{~d}$ after treatment (day 28) delayed type of hypersensitivity reaction (DTH) was determined using the Multitest Mérieux ${ }^{\mathrm{TM}}$ test system (Institut Mérieux $\mathrm{GmbH}$, Leimen, Germany). DTH response to recall antigens reflects a type 1 cytokine-mediated immune reaction (14).

Skin biopsies (4-mm punch biopsies) were obtained $4 \mathrm{~d}$ before IL10 therapy, at day 8 , and at day 24 (end of therapy) for histological and immunohistochemical examination as well as for determination of IL-10 mRNA expression.

Immunological characterization of peripheral blood leukocytes

1. Abbreviations used in this paper: APCs, antigen-presenting cells; AU, arbitrary units; DTH, delayed type of hypersensitivity; PASI, psoriasis area and severity index. was performed immediately before IL-10 therapy (day 1), 6 and $24 \mathrm{~h}$ after the first dose, and at days 5, 8, 15, 22, and 28 (4 d after the end of therapy). For assessing IL-10-induced immunodepression, HLA-DR expression on monocytes and plasma levels of IL-12 p40 as well as endotoxin-induced TNF- $\alpha$ and IL-12 heterodimer secretion in whole blood cultures were investigated. For assessing type 1/type 2 cytokine balance, $\operatorname{IgE}$ serum levels and the ex vivo intracellular cytokine formation capacity of $\mathrm{CD}^{+}$and $\mathrm{CD} 4^{-} \mathrm{T}$ cells were determined.

Histology and immunohistochemistry. The histological investigations included the evaluation of the main psoriatic parameters such as acanthosis, hyperkeratosis, and parakeratosis, the mitotic activity of the epidermis, papillary edema, dilation and tortuosity of capillaries, and neutrophils in the dermis, the stratum spinosum, as well as in the horny layer, respectively.

Immunohistochemical investigations were carried out using monoclonal antibodies against CD8 (C8/144B), CD79a (JCB 117), and CD3 (A 0452, polyclonal) (all Dako, Hamburg, Germany), as well as CD1a (O10; Coulter-Immunotech, Krefeld/Hamburg, Germany), and Ki67 (MIB-1; Dianova, Hamburg, Germany).

Semiquantitative cytokine $m R N A R T-P C R$. PCR analyses for the quantification of cytokine mRNA expression were performed as described in detail elsewhere $(29,30)$. Briefly, total RNA was extracted from skin biopsies and from Ficoll-Hypaque (Pharmacia, Uppsala, Sweden) separated PBMC, respectively. Quantification of cytokine cDNA derived from this RNA was carried out using multispecific control fragments as an internal standard for competitive PCR. First, the cDNA samples to be compared were equilibrated according to their glyceraldehyde-3-phosphate-dehydrogenase cDNA content. Then, the relative concentration of IL-10 and TNF- $\alpha$ cDNA in each sample was estimated from the concentration of control fragment DNA that achieved equilibrium between its own amplification and that of the target cDNA. The concentrations were determined in arbitrary units (AU). One AU was defined as the lowest concentration of control fragment that yielded a detectable amplification product given the primer pair and the PCR conditions used (30). Control RTPCR without template DNA was performed in all experiments to exclude contamination. As an additional control, reverse transcriptase was omitted from the reaction mixture during cDNA synthesis to prove the absence of genomic DNA. The following oligonucleotides (29) were used as primer pairs (sense/antisense): GAPDH: GCAGGGGGGAGCCAAAAGGG/TGCCAGCCCCAGCGTCAAAG; IL-10: CTGAGAACCAAGACCCAGACATCAAGG/CAATAAGGTTTCTCAAGGGGCTGG; $T N F-\alpha$ : CTCTGGCCCAGGCAGTCAGA/GGCGTTTGGGAAGGTTGGAT.

Levels of IL-12 p40 in plasma. Plasma supernatants were harvested from EDTA-anticoagulated venous blood samples within $15 \mathrm{~min}$ and were stored at $-70^{\circ} \mathrm{C}$ until cytokine analysis. IL-12 concentrations in plasma were analyzed using the IL-12 p40 ELISA from Medgenix (Ratingen, Germany).

$I g E$ levels in serum. Serum supernatants were harvested from venous blood samples. IgE concentrations were determined using the Cobas ${ }^{\mathrm{TM}}$ core IgE total EIA (Hoffmann-La Roche, Grenzach-Wyhlen, Germany).

Monocytic HLA-DR expression. Monocytic HLA-DR expression in isolated PBMC was determined using monoclonal antibodies (phycoerythrin-labeled anti-HLA-DR [L243], FITC-labeled anti-CD14 [M $\varnothing \mathrm{P} 9]$ ), a FACScan ${ }^{\circledR}$ machine, and LYSYS II ${ }^{\mathrm{TM}}$ software (all from Becton Dickinson, Heidelberg, Germany). Briefly, $5 \times 10^{5}$ PBMC were incubated with $20 \mu \mathrm{l}$ 1:10 diluted antibodies in a total of $70 \mu \mathrm{l}$ for 20 min in the dark. After washing, the mean fluorescence intensity of HLA-DR staining was determined in the $\mathrm{CD} 14^{+}$monocyte population (31).

Ex vivo endotoxin-induced cytokine secretion. For analysis of ex vivo monokine synthesis, whole blood was diluted 1:2 with heparinized RPMI 1640 medium (Biochrom KG, Berlin, Germany) and stimulated with $100 \mathrm{ng} / \mathrm{ml}$ endotoxin from Escherichia coli 0127:B8 (Sigma, Deisenhofen, Germany) at $37^{\circ} \mathrm{C}$ and $5 \% \mathrm{CO}_{2}$ for 4 and $24 \mathrm{~h}$ (31). Culture supernatants were stored at $-70^{\circ} \mathrm{C}$ until measurement 


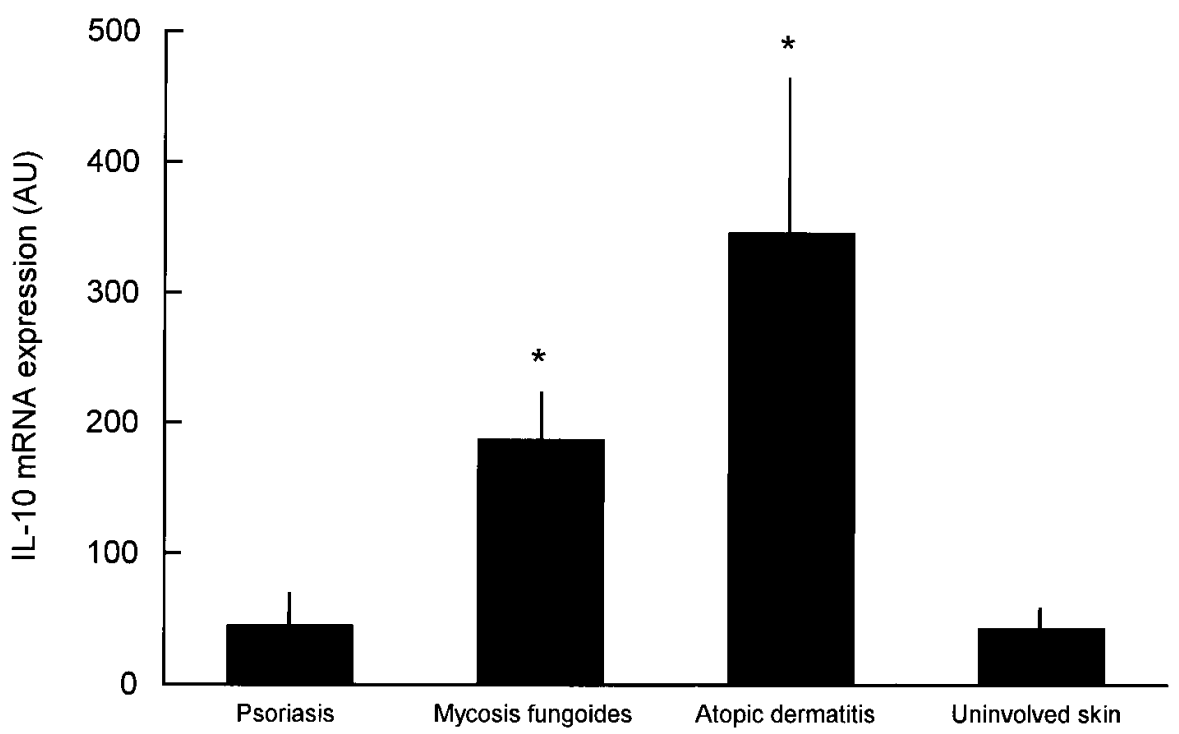

Figure 1. Low IL-10 mRNA expression in psoriatic skin lesions. Cutaneous IL-10 mRNA expression was analyzed in biopsies from patients with psoriasis $(n=7)$, plaque and tumor stage mycosis fungoides $(n=9)$, and atopic dermatitis $(n=5)$. Moreover, nonlesional skin samples of eight patients (two mycosis fungoides, three psoriasis, three atopic dermatitis) were analyzed. RNA preparation, reverse transcription, and semiquantitative RT-PCR were carried out as described in Methods. IL-10 mRNA concentrations are given in AU as mean \pm SEM. $* P<0.05$ vs. psoriasis and nonlesional skin; Mann-Whitney U test. of cytokine levels by commercially available ELISA kits. TNF- $\alpha$ concentration (Medgenix) was determined in supernatants of 4-h culture, whereas IL-12 heterodimer (Quantikine ${ }^{\mathrm{TM}}$; DPC Biermann, Bad Nauheim, Germany) and IL-10 (Cytoscreen ${ }^{\mathrm{TM}}$; Laboserv, Giessen, Germany) secretion were investigated after $24 \mathrm{~h}$ of endotoxin stimulation. For assessment of cytokine secretion capacity per monocyte, cell numbers in whole blood were determined from white blood cell counts (Neubauer chamber; Neubauer, Marienfeld, Germany) and differential blood smear.

Type 1/type 2 cytokine production capacity of $C D 4^{+}$and $C D 4^{-} T$ cells. The production of the type 1 cytokines IFN- $\gamma$, TNF- $\alpha$, IL-2 and the type 2 cytokines IL-4, IL-5, and IL-10 was assessed in $\mathrm{CD}^{+}{ }^{+} \mathrm{CD} 4^{+}$ and $\mathrm{CD} 3^{+} \mathrm{CD}^{-} \mathrm{T}$ cells using ex vivo stimulation in whole blood with subsequent intracellular cytokine staining and flow cytometry.

Briefly, heparinized whole blood was diluted 1:2 with heparinized RPMI 1640 medium (Biochrom KG) and stimulated with PMA (25 $\mathrm{ng} / \mathrm{ml}$; Sigma) and the calcium ionophore ionomycin ( $1 \mu \mathrm{g} / \mathrm{ml}$; Sigma) in the presence of the cytokine secretion inhibitor Brefeldin A (10 $\mu \mathrm{g} / \mathrm{ml}$; Becton Dickinson) for $4 \mathrm{~h}\left(37^{\circ} \mathrm{C}, 5 \% \mathrm{CO}_{2}\right)$. Thereafter, T cell surface antigens were stained using FITC-labeled anti-CD4 and PECy5-labeled anti-CD3 monoclonal antibodies (both from Coulter-
Immunotech) in a final concentration of $5 \%(\mathrm{vol} / \mathrm{vol})$ for $20 \mathrm{~min}$ at $4^{\circ} \mathrm{C}$ in the dark. Then, erythrocyte lysis and cell fixation was performed using FACS ${ }^{\circledR}$ lysing solution (Becton Dickinson). After permeabilization of leukocytes by FACS $^{\circledR}$ permeabilizing solution (Becton Dickinson), cells were intracellularly stained with the respective phycoerythrin-labeled anticytokine monoclonal antibodies $(20 \% \mathrm{vol} /$ vol) for $30 \mathrm{~min}$ at room temperature in the dark. After a washing step, measurement and analysis of 20,000 cells for each cytokine were done using a FACScan ${ }^{\circledR}$ machine and LYSYS II $^{\mathrm{TM}}$ software.

Phycoerythrin-labeled monoclonal antibodies against the following cytokines were used for intracellular staining: IFN- $\gamma$ and IL-2 (FASTIMMUNE; Becton Dickinson); TNF- $\alpha$, IL-4, IL-5, and IL-10 (PharMingen, Hamburg, Germany). The percentage of cytokine-positive cells was determined in both the $\mathrm{CD}^{+}$and $\mathrm{CD} 4^{-}$subsets of the $\mathrm{CD}^{+} \mathrm{T}$ cell population. For delimiting cytokine-positive and -negative cells, the respective isotype controls (IgG1 and IgG2a; Becton Dickinson) were used.

Statistical analysis. Data are presented as mean \pm SEM. Statistical analysis was performed using the Mann-Whitney U test for the comparison of groups.

Since for the three psoriatic patients undergoing IL-10 therapy

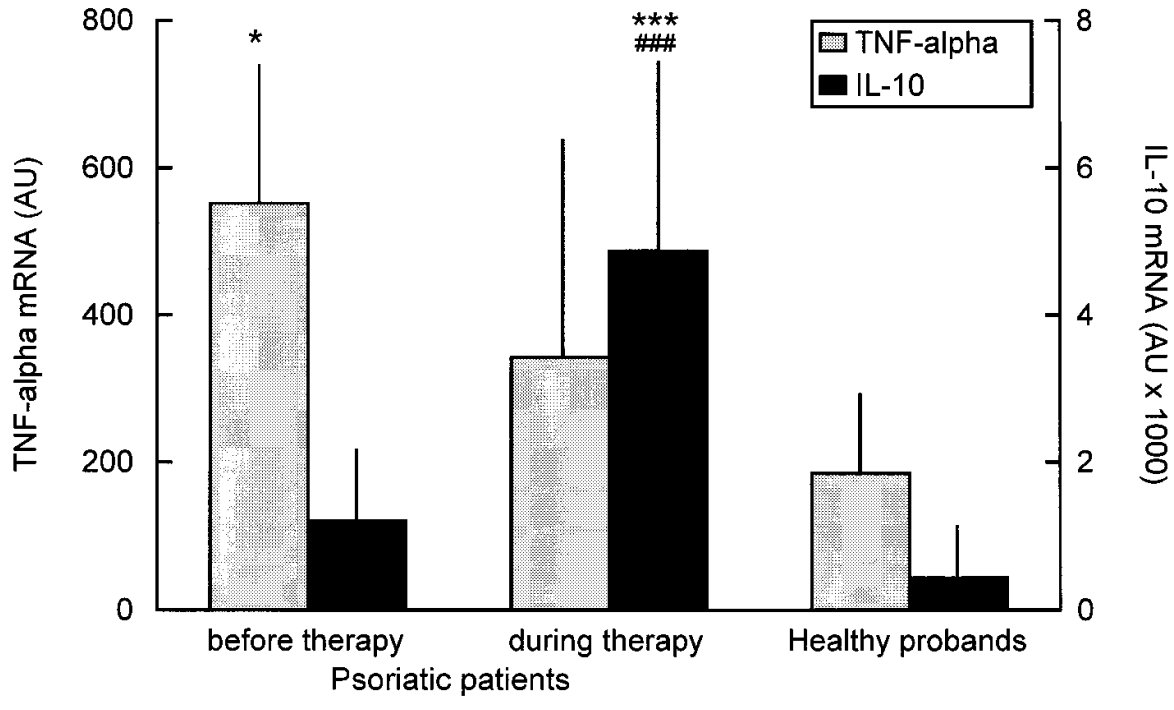

Figure 2. Decreasing TNF- $\alpha$ but increasing IL-10 mRNA expression in response to initial conventional psoriasis therapy. Cytokine mRNA expression was analyzed in freshly prepared PBMC from psoriatic patients before therapy $(n=6)$ and during the initial phase of conventional therapy $(n=7)$ as well as from healthy volunteers $(n=12)$. RNA preparation, reverse transcription, and semiquantitative RT-PCR were carried out as described in Methods to determine IL-10 gene expression. IL-10 mRNA concentrations are given in $\mathrm{AU}$ as mean \pm SEM. $* * * P<0.001, * P<0.05$ vs. healthy probands; Mann-Whitney U test. ${ }^{\# \# \# P} P<0.001$ vs. psoriatic patients before therapy; Mann-Whitney U test. 


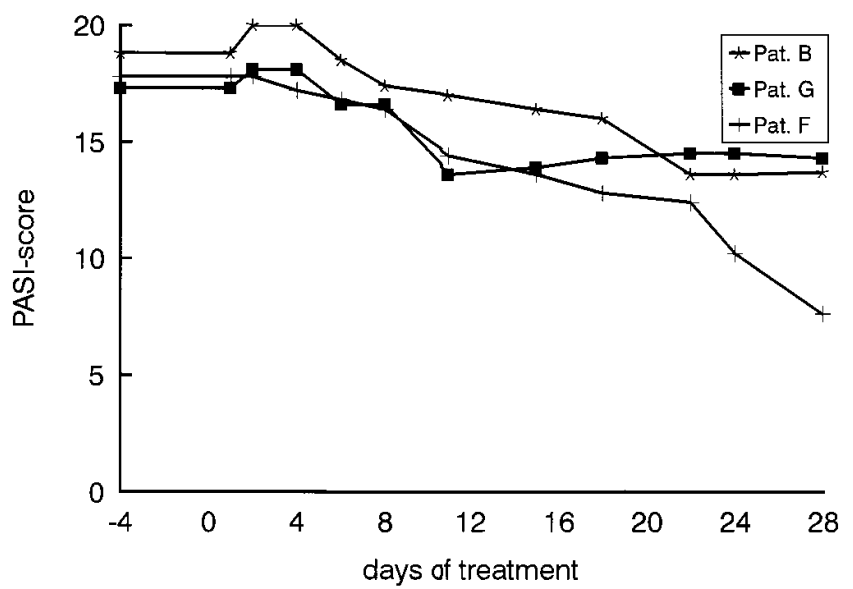

Figure 3. Decreasing disease activity during IL-10 therapy. The PASI (27) was determined in three psoriatic patients undergoing IL-10 therapy for $24 \mathrm{~d}$. In patients F and G, IL-10 was subcutaneously injected under a psoriatic plaque whereas it was injected in nonlesional, subcutaneous tissue in patient $\mathrm{B}$.

statistical analysis was not possible, for additional information mean values in follow-up were indicated with filled boxes and open circles if for all three patients results were higher or lower than before therapy, respectively.
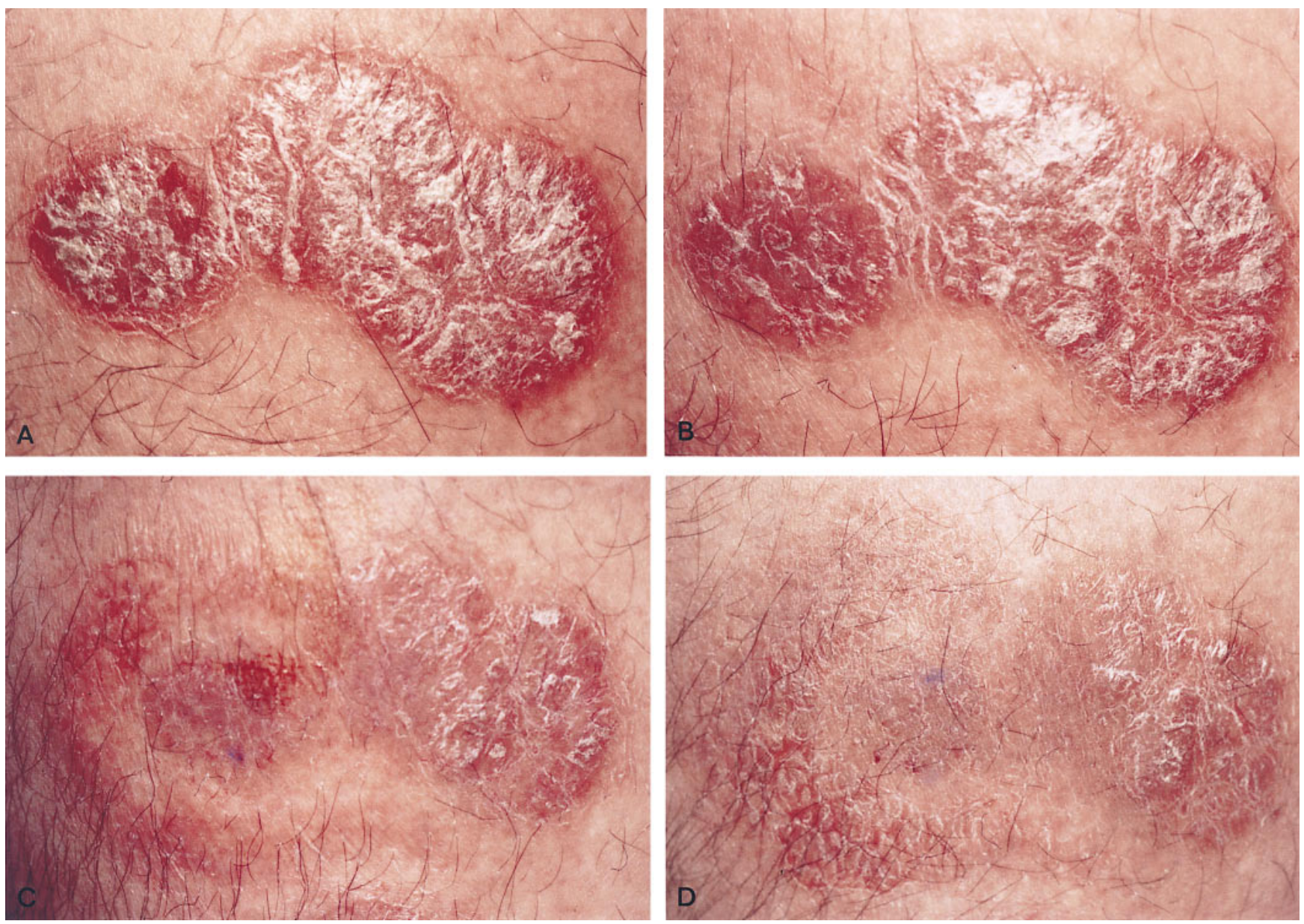

Figure 4. Local effects of IL-10 administration in patient F. IL-10 was injected daily within the left skin lesion. The figure shows the situation in patient $\mathrm{F}$ before $(A)$, during (day $8, B$; day $15, C$ ), and at the end of IL-10 therapy (day $24, D$ ). 
tional antipsoriatic treatment reversed this pattern; therefore, lower TNF- $\alpha$ but significantly higher IL-10 mRNA levels were found (Fig. 2). This strongly suggests an association of IL-10 increase and TNF- $\alpha$ decrease with efficient initial antipsoriatic therapy.

\section{Clinical response to IL-10 therapy}

To test whether IL-10 has direct antipsoriatic activity, we treated three patients with daily subcutaneous administrations of recombinant human IL-10 $(8 \mu \mathrm{g} / \mathrm{kg} / \mathrm{d})$ over a period of $24 \mathrm{~d}$. The treatment was well tolerated. There was no evidence of any adverse side effects. All patients reported the loss of skin itching. A decrease of the PASI score was observed in all patients. However, the degree of the antipsoriatic effect was heterogeneous and no complete healing was reached during the period of monitoring (Fig. 3).

Patient F showed a strong local response to IL-10 subcuta- neously injected under a psoriatic plaque (Fig. 4). Interestingly, the improvement of this plaque was associated with subsequent development of a peripheral erythematous ring (Fig. 4). This may indicate the induction of a reactive process at the margin of the lesion which is reactive to high IL-10 concentration present in the subcutaneous tissue underlying the lesion. Beside the local effects, this patient showed also significant improvement of all other lesions, indicating a systemic therapeutic effect of IL-10 (Fig. 5). Remarkably, further improvement was observed in this patient even after the end of IL-10 treatment. Moderate antipsoriatic effects were observed in patient $\mathrm{B}$, mainly showing a significantly decreasing scaling and infiltration (Fig. 6). The antipsoriatic effect in patient $G$ was only marginal (not shown). No rebound effect was observed in any patient during the period immediately after treatment.

The extent of the ultrasound-measured echopoor band as an objective parameter for plaque thickness corresponded well
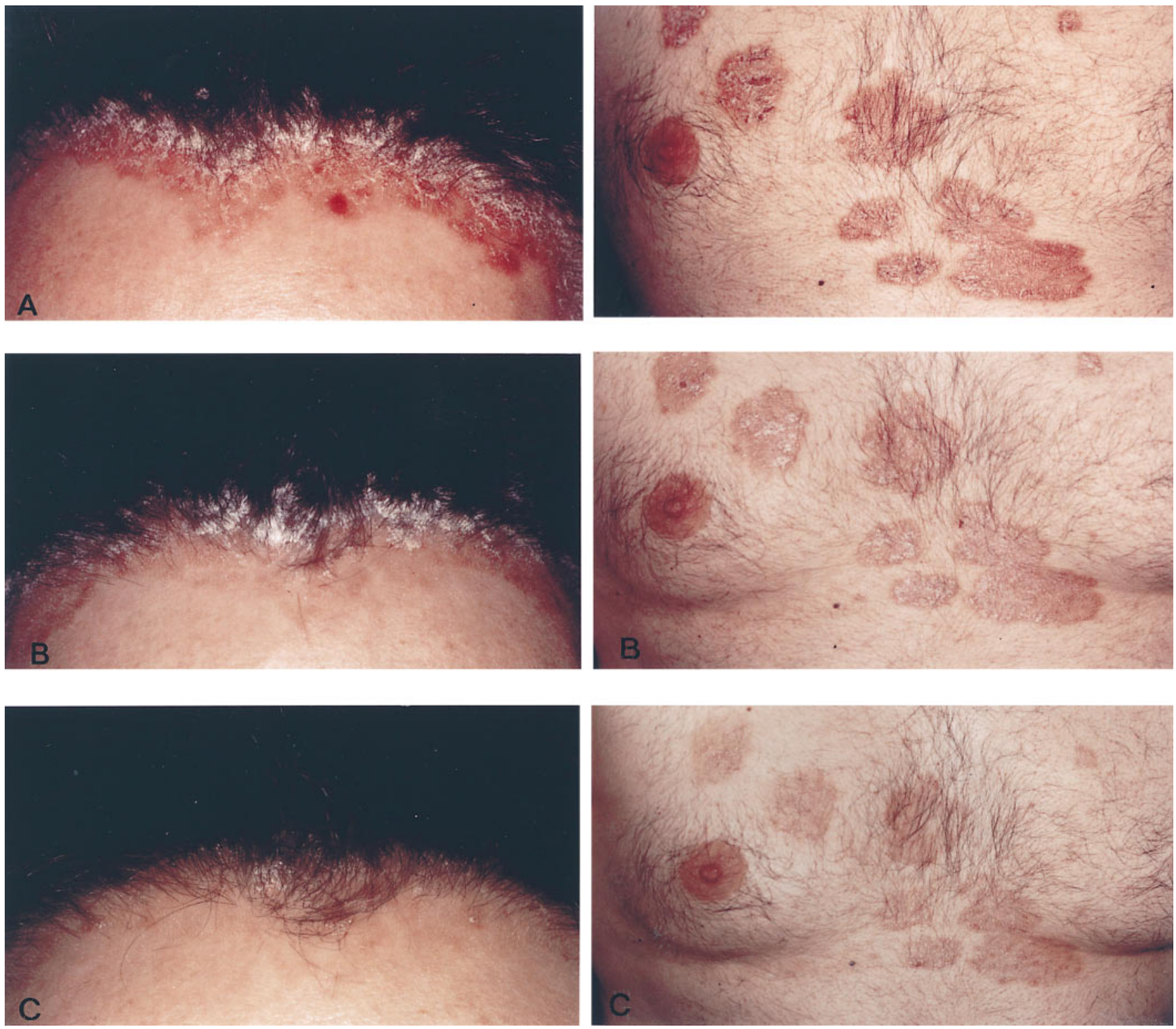

Figure 5. Marked systemic antipsoriatic effect of intralesional IL-10 administration in patient F. Typical, locally untreated skin lesions are shown before $(A)$, during (day 15, B), and at the end of therapy (day 24, $C$ ). Lesions at the forehead/hair border and the breast are shown. 

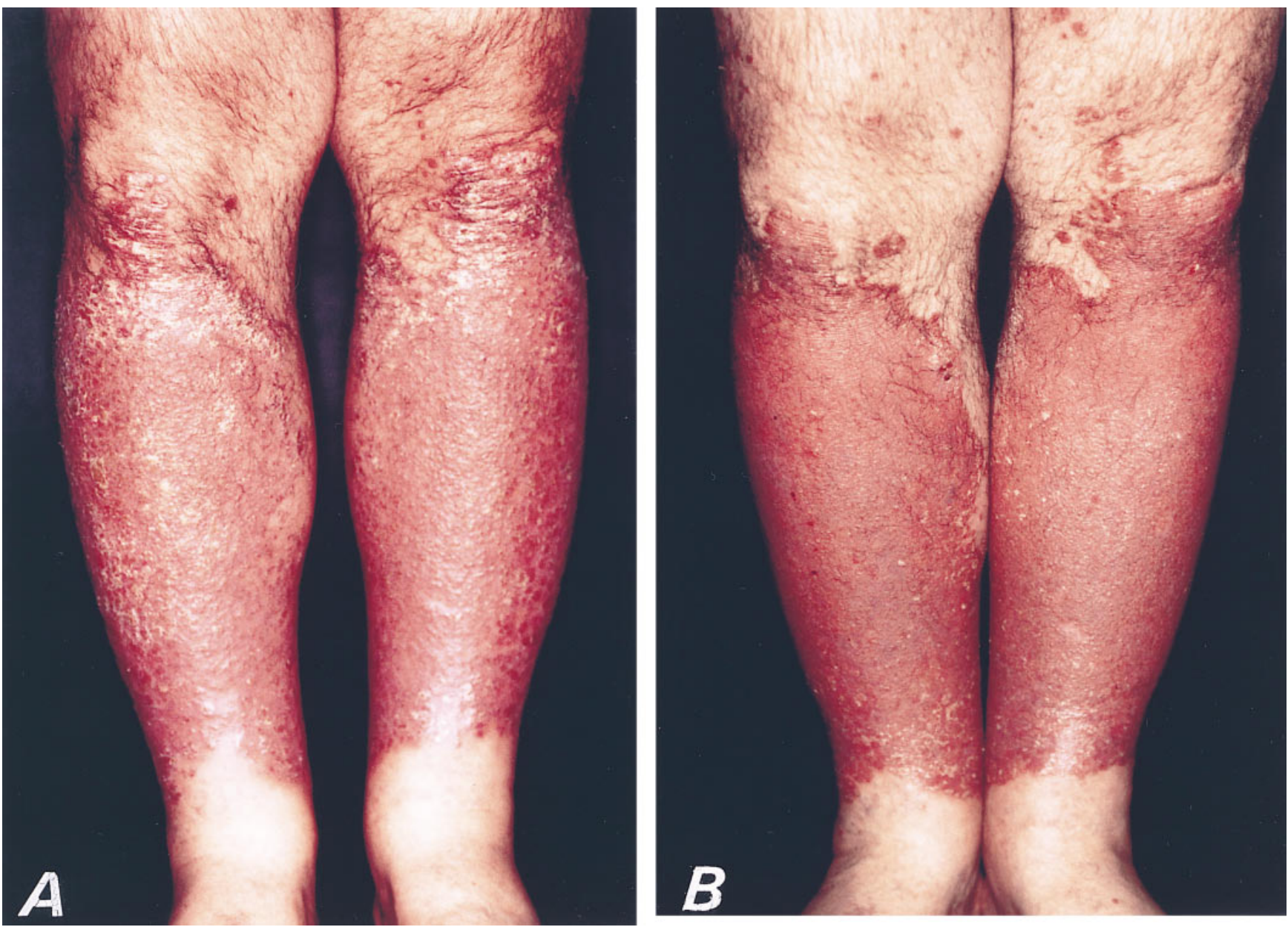

Figure 6. Moderate antipsoriatic effect of nonlesional IL-10 administration in patient B. Typical skin lesions in patient B before $(A)$ and at the end of therapy at day $24(B)$.

to the clinical parameters. In patient $\mathrm{F}$, the echopoor band completely disappeared in the IL-10-treated plaque (Fig. 7). Moreover, we found a significant reduction in the vehicletreated as well as in not locally treated plaques, indicating systemic effects of IL-10. However, there was a considerable difference between the IL-10-treated plaque and these lesions, arguing for the direct, local antipsoriatic activity of IL-10. The decrease of the echopoor band was less extensive in the two other patients, corresponding to the clinical results (PASI score). So at the end of therapy (day 24) the reduction of the echopoor band in patient $\mathrm{B}$, who received nonlesional IL-10 injections, was between 10 and $30 \%$ in the three plaques investigated. Only marginal effects were observed in patient $\mathrm{G}$.

Finally, histological investigation demonstrated a decrease of epidermal thickness along with a decrease of parakeratosis and Munro's abscesses (Fig. 8), whereas the morphology of the papillary vessels was the same as before. The quantity of the infiltrate decreased without accentuating any special cell population, as investigated by immunohistochemistry.

\section{Immunological effects of IL-10 therapy}

Signs for systemic immunodepression. So far, only data from immunological effects of a single IL-10 injection have been published (25). We wondered which effects a long-term (24 d) IL-10 treatment may induce.

IL-10 administration continuously suppressed monocytic HLA-DR expression as well as IL-12 p40 plasma levels, indicating persistent immunodepression (Fig. $9 A$ ).

When looking at the TNF- $\alpha$ and IL-12 heterodimer secretion in whole blood cultures stimulated with endotoxin, an only transient depression was found at $6 \mathrm{~h}$ after the first IL-10 administration (data not shown). Since monocytes are responsible for the proinflammatory cytokine production after endotoxin stimulation in whole blood cultures, the values were corrected by monocyte counts (see Fig. $9 \mathrm{~B}$ ). A widely sustained depression of cytokine secretion capacity per monocyte was found (Fig. $9 \mathrm{~B}$ ).

Type 2 shift resulting from lasting induction of $I L-4, I L-5$, and IL-10 producing $T$ cells. It has been shown that IL-10 is able to suppress or even to anergize type $1 \mathrm{~T}$ cells in vitro. We wondered whether long-term IL-10 administration influences the type $1 /$ type 2 balance in vivo.

The type 1/type 2 cytokine formation capacity of peripheral blood $\mathrm{T}$ cells during IL-10 therapy was investigated by flow cytometry. A strong decrease of IFN- $\gamma$ producing $\mathrm{CD}^{+}{ }^{+} \mathrm{T}$ cells was demonstrated at $6 \mathrm{~h}$ followed by an increase at day 2 indi- 

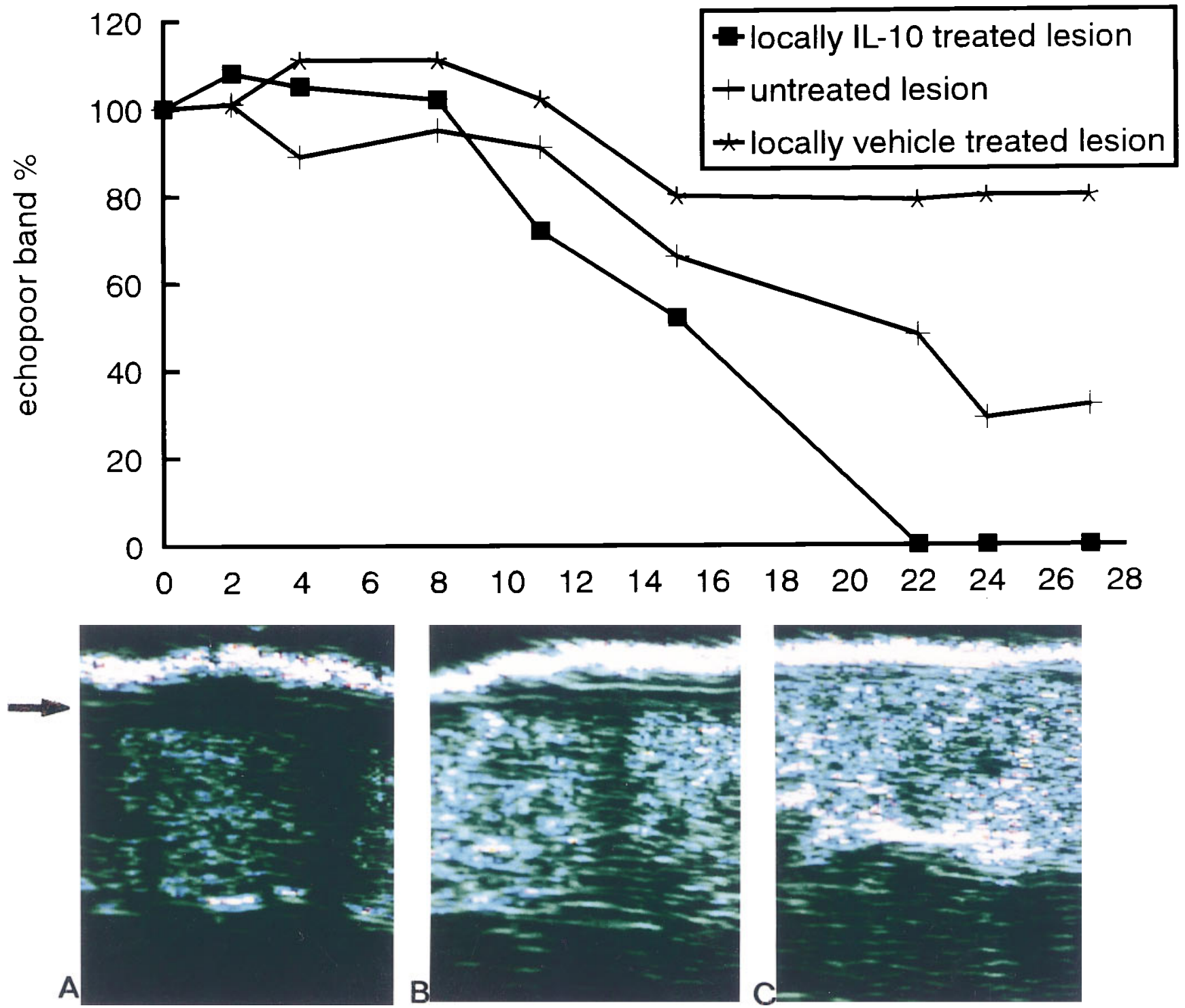

Figure 7. Reduction of the echopoor band was most intensive directly at the injection site of IL-10. The echopoor band was monitored by ultrasound as an objective parameter for plaque thickness in patient F. The upper part of the figure shows the follow-up in the IL-10-treated and the vehicle-treated lesions as well as in an untreated lesion. The pretreatment value was considered as $100 \%$. The lower part of the figure shows the ultrasound pictures from the plaque directly injected with IL-10 before $(A)$, at day $15(B)$, and after therapy (day $24, C)$. The arrow indicates the echopoor band measured.

cating counterregulation (Fig. $10 \mathrm{~A}$ ). This pattern corresponds to that of the monocyte-derived type 1 cytokine IL-12 after endotoxin stimulation (Fig. $9 \mathrm{~B}$ ) and was also seen for IL-2 and $\mathrm{TNF}-\alpha$ secreting $\mathrm{T}$ helper cells (not shown). In contrast to IFN- $\gamma$ producing $T$ cells, the percentage of IL- 2 and TNF- $\alpha$ producers remained diminished even after the end of IL-10 therapy (day 28) (Table I). In CD4 ${ }^{-} \mathrm{T}$ cells we observed only a marginal decrease of $\mathrm{TNF}-\alpha$ expressing cells in all three patients (Table I).

The percentage of IL-4 producing $\mathrm{CD}^{+} \mathrm{T}$ cells increased in all three patients beginning with day 2 (Fig. $10 A$ ). Although some counterregulation was indicated by a redecrease at day 8 , the proportion of IL-4 producers remained elevated through the whole treatment period and even at $4 \mathrm{~d}$ after cessation of IL-10 therapy. Accordingly, the IFN- $\gamma /$ IL-4 ratio was lower than before therapy during the whole observation period in all three patients. Similarly, IL-10 treatment led to a lasting increase of IL-5 and IL-10 producing T helper cells (Table I). Moreover, a marked and lasting induction of type $2 \mathrm{~T}$ cell cytokine secretion capacity was also demonstrable for the CD4- $\mathrm{T}$ cell population (Table I).

Taken together, IL-10 induced a shift from type 1 to type 2 cytokine formation in $\mathrm{T}$ cells which persisted even after cessation of treatment. Accordingly, increasing $\mathrm{IgE}$ serum levels (Fig. $10 \mathrm{~B}$ ) and a tendency for higher counts of eosinophilic granulocytes in peripheral blood (not shown) were observed. The plasma levels of the other Ig classes and of IgG subclasses were not altered (not shown).

Depression of intracutaneous type 1 immune response and restoration of intralesional IL-10 mRNA expression. Direct ev- 
Table I. Intracellular Cytokine Formation Capacity of $\mathrm{CD}^{+}$ and $C D 4^{-} T$ Cells before and $4 d$ after the End of IL-10 Therapy

\begin{tabular}{|c|c|c|c|c|}
\hline \multirow[b]{2}{*}{ Cytokines } & \multicolumn{2}{|c|}{$\mathrm{CD}^{+}{ }^{+} \mathrm{T}$ cells } & \multicolumn{2}{|c|}{$\mathrm{CD} 4^{-} \mathrm{T}$ cells } \\
\hline & Before & Day 28 & Before & Day 28 \\
\hline & $\%$ & $\%$ & $\%$ & $\%$ \\
\hline IFN- $\gamma$ & $17.0 \pm 3.4$ & $20.7 \pm 1.6$ & $52.3 \pm 5.9$ & $53.6 \pm 8.1$ \\
\hline TNF- $\alpha$ & $17.4 \pm 6.0$ & $7.1 \pm 2.2 *$ & $22.5 \pm 6.6$ & $17.0 \pm 3.5^{*}$ \\
\hline IL-2 & $56.7 \pm 4.9$ & $28.6 \pm 7.3^{*}$ & $23.7 \pm 6.0$ & $23.0 \pm 8.4$ \\
\hline IL-4 & $2.7 \pm 1.4$ & $8.1 \pm 1.4^{\ddagger}$ & $3.9 \pm 2.6$ & $14.1 \pm 2.6^{\ddagger}$ \\
\hline IL-5 & $4.6 \pm 0.9$ & $20.1 \pm 2.9^{\ddagger}$ & $6.3 \pm 1.5$ & $23.8 \pm 3.6^{\ddagger}$ \\
\hline IL-10 & $0.9 \pm 0.1$ & $7.7 \pm 0.8^{\ddagger}$ & $2.9 \pm 2.7$ & $14.1 \pm 4.1^{\ddagger}$ \\
\hline IFN- $\gamma /$ IL-4 ratio & $8.3 \pm 2.4$ & $2.6 \pm 0.2 *$ & $27.4 \pm 12.4$ & $3.9 \pm 0.2 *$ \\
\hline
\end{tabular}

In three psoriatic patients undergoing IL-10 therapy, intracellular cytokine formation capacity of $\mathrm{T}$ cells was determined using triple-color flow cytometry after $4 \mathrm{~h}$ of whole blood stimulation with PMA/ionomycin as described in Methods. For each cytokine the percentage of positive cells before and $4 \mathrm{~d}$ after cessation of IL-10 therapy (day 28) is given as mean $\pm \mathrm{SEM}$ for both $\mathrm{CD} 4^{+}$and the $\mathrm{CD} 4^{-} \mathrm{T}$ cell population. *Values were higher than before IL-10 therapy for all three patients; *values were lower than before IL-10 therapy for all three patients.

idence for in vivo depression of type 1 immune response was yielded by investigating the DTH response to seven recall antigens (Multitest Mérieux) in healthy skin. In all patients, a loss of at least one positive reaction was found (Fig. $11 A$ ). This may be of special importance, since after repeated application of recall antigens a booster effect rather than a loss of reactivity would have been expected. The decrease in the number of positive reactions resulted exclusively from the loss of those reactions which were weak (size of erythema $<4 \mathrm{~mm}$ ) before IL-10 therapy.

Furthermore, we investigated the intralesional pattern of IL-10 mRNA expression in the three psoriatic patients undergoing IL-10 therapy. Surprisingly, exogenous IL-10 administration also restored the relative IL-10 mRNA deficiency in psoriatic plaques (Fig. $11 \mathrm{~B}$ ). This is compatible with a shift to a local type 2 cytokine pattern. Remarkably, patient F, who responded best to therapy, showed the most dramatic rise in cutaneous IL-10 gene expression. Further investigations are necessary to identify the cellular origin of the increasing IL-10 mRNA expression (infiltrating $\mathrm{T}$ cells, monocytes/macrophages, keratinocytes).

\section{Discussion}

Here we show that cutaneous IL-10 mRNA expression in psoriasis is significantly lower than in other inflammatory dermatoses and that IL-10 administration may have antipsoriatic effects.

The level of cutaneous IL-10 mRNA expression in psoriatic lesions was not distinguishable from healthy human skin, as opposed to significant overexpression of several proinflammatory cytokines $(4,5,15-17)$. Our results correspond well with findings regarding low cutaneous IL-10 protein expression, as determined by immunohistochemistry (33) and by measurement in suction blister fluid (34). In addition to this lo-
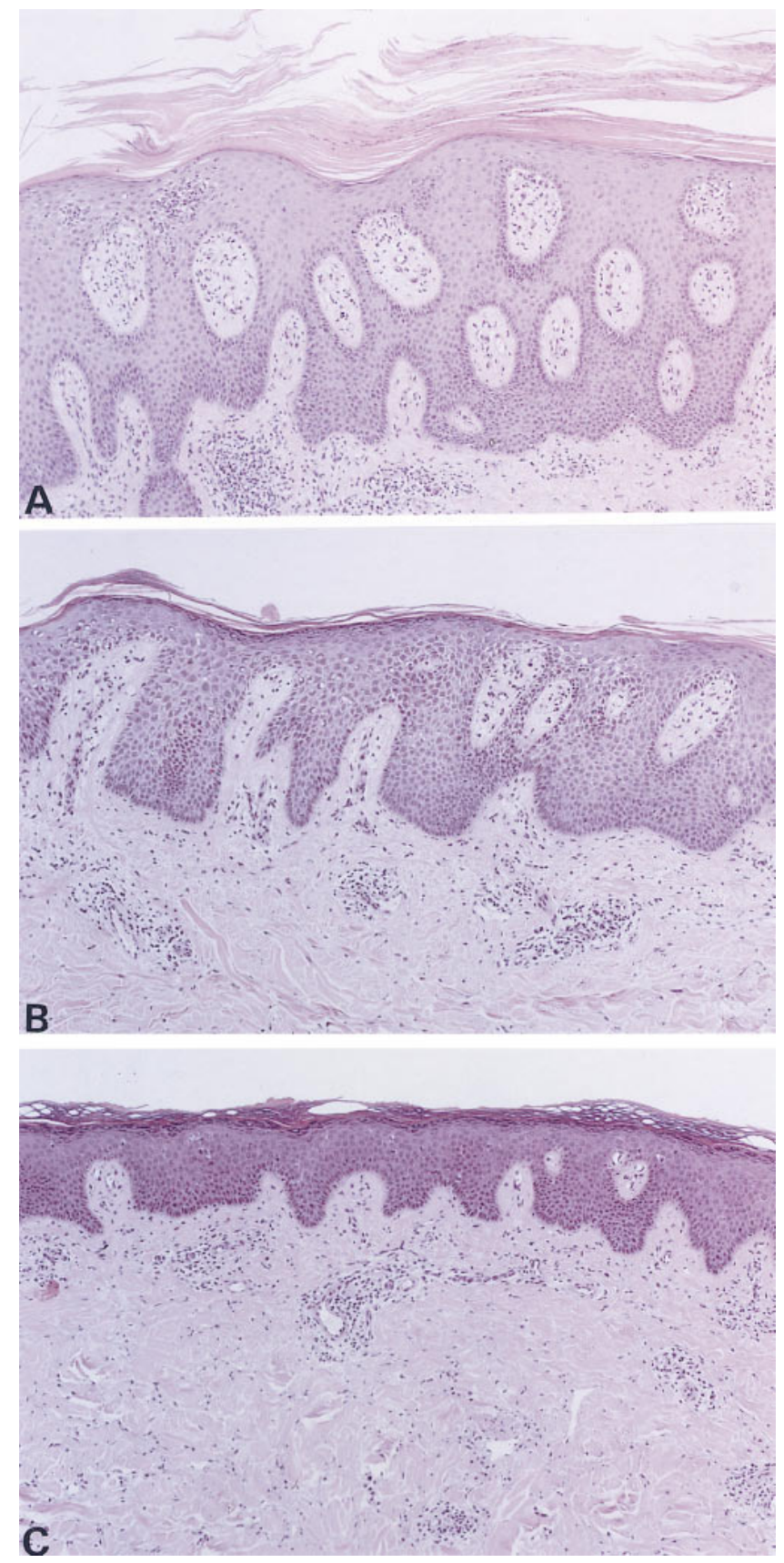

Figure 8. Histological examination. Intralesional skin biopsy specimens were obtained before $(A)$, at day $8(B)$, and at the end of IL-10 therapy (day 24, $C$ ) in patient $\mathrm{F}$. A decrease of epidermal thickness along with a decrease of parakeratosis and Munro's abscesses as well as a moderate reduction of the infiltrate is demonstrable. Hematoxylin and eosin staining, original magnification $\times 16$.

cal IL-10 deficiency, endotoxin-stimulated whole blood from psoriatic patients showed a tendency for lower IL-10 formation capacity. Taken together IL-10 deficiency may be a central phenomenon in psoriasis.

For several reasons we believe that this relative IL-10 deficiency may be of major importance for the pathogenesis of psoriasis and that its normalization would be beneficial. First, it has been shown in vitro that several sufficient antipsoriatic 


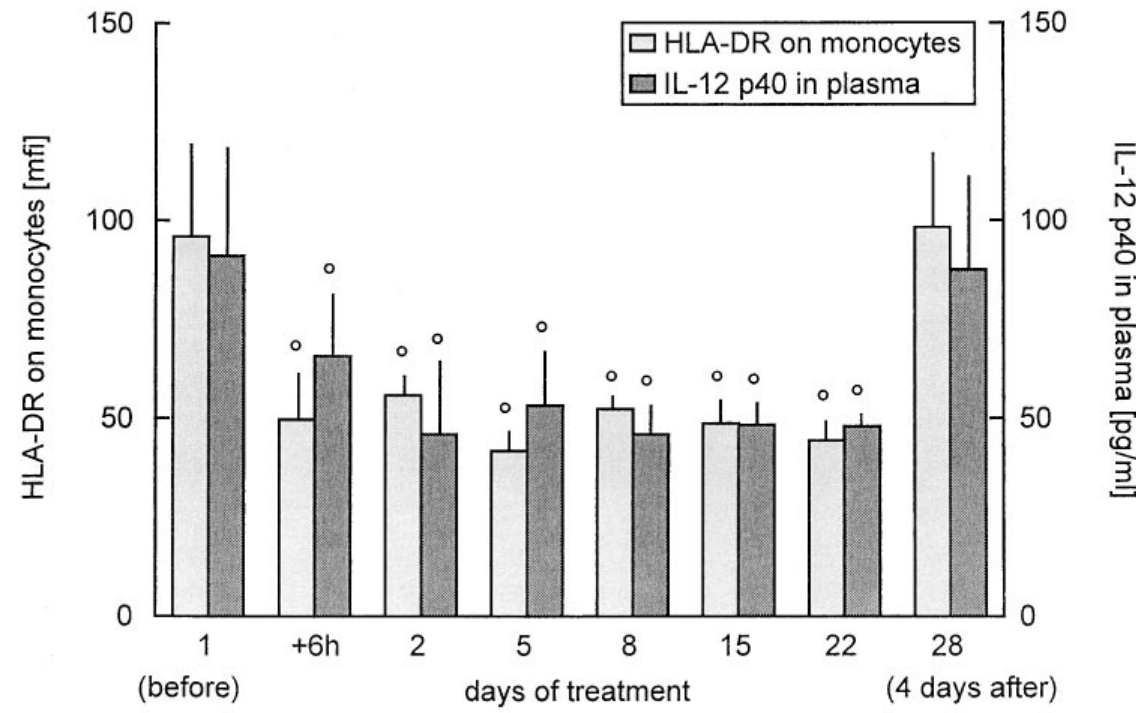

B

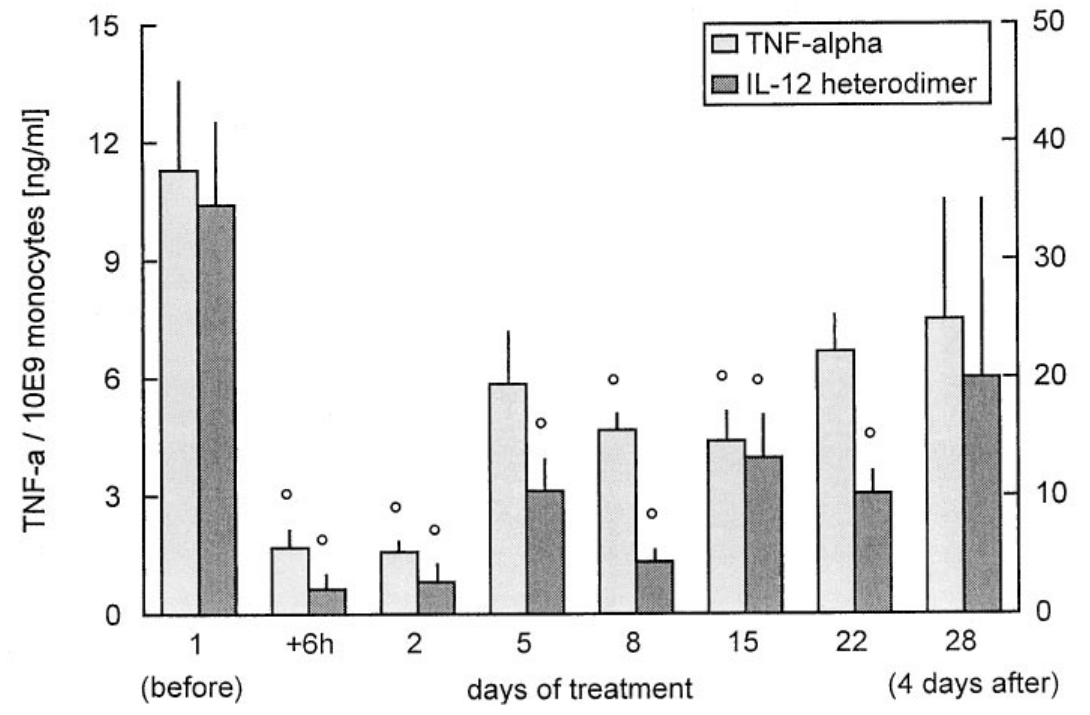

Figure 9. IL-10 therapy suppressed monocytic HLA-DR expression, IL-12 and TNF- $\alpha$ secretion capacity, and IL-12 p40 plasma levels. $(A)$ In the three psoriatic patients undergoing IL-10 therapy, monocytic HLA-DR expression in freshly isolated PBMC and IL-12 p40 plasma levels were determined by flow cytometry and ELISA, respectively, as described in Methods. (B) In the three psoriatic patients undergoing IL-10 therapy, TNF- $\alpha$ and IL-12 heterodimer secretion was determined in whole blood cultures after 4 and $24 \mathrm{~h}$ of endotoxin $(100 \mathrm{ng} / \mathrm{ml})$ stimulation, respectively. The cytokine production values were corrected by monocyte counts ([Gpt/l], before therapy: $0.30 \pm 0.1 ; 6 \mathrm{~h}$ : $0.80 \pm 0.27$; day $2: 1.29 \pm 0.23$; day 5 : $0.62 \pm 0.06$; day 8: $0.67 \pm 0.11$; day 15 : $0.56 \pm 0.04$; day 22: $0.42 \pm 0.05 ; 4$ d after therapy: $0.62 \pm 0.33)$. The data of the three psoriatic patients are given as mean \pm SEM. Open circles, Values were lower than before IL-10 therapy for all three patients.

therapies, e.g., UV radiation (35) and monomethylfumarat (13), led to an increase of IL-10 production by several cell types. Moreover, here we demonstrate in vivo higher IL-10 mRNA expression in PBMC during conventional antipsoriatic therapy. Second, we have shown previously that cAMP-elevating drugs (e.g., iloprost, pentoxifylline) led to an upregulation of IL-10 (36). Interestingly, it was reported that pentoxifylline (37) and isoprenaline (38) are effective in the treatment of psoriasis. Third, our hypothesis would explain several well known clinical observations: Inhibitors of the $\beta$-adrenergic receptor (e.g., propranolol) or the cyclooxygenase (e.g., indomethacin) (39) often lead to exacerbation of psoriasis. These drugs diminish intracellular cAMP formation and presumably are associated with IL-10 decrease. Moreover, direct support of a type 1 cytokine pattern by IFN- $\alpha$ (40) or IFN- $\gamma$ application (3) as well as IFN- $\gamma$-elevating drugs like lithium (41) are known to induce or to exacerbate psoriasis, and it is well established that IFN- $\gamma$ inhibits IL-10 expression (22). On the other hand, pregnancy often leads to depression of type 1 cytokines (42), and the majority of psoriatic women who became pregnant experience an improvement in their disease activity (43).

Since IL-10 dysregulation may play a key role in psoriasis, we investigated the therapeutic effect of IL-10 in a limited number of patients with severe psoriasis. Indeed, IL-10 therapy showed considerable antipsoriatic effects. Remarkably, subcutaneous injection of IL-10 directly under the psoriatic plaque led to complete clearance of the lesion in one of two patients. Moreover, systemic antipsoriatic effects were ob- 

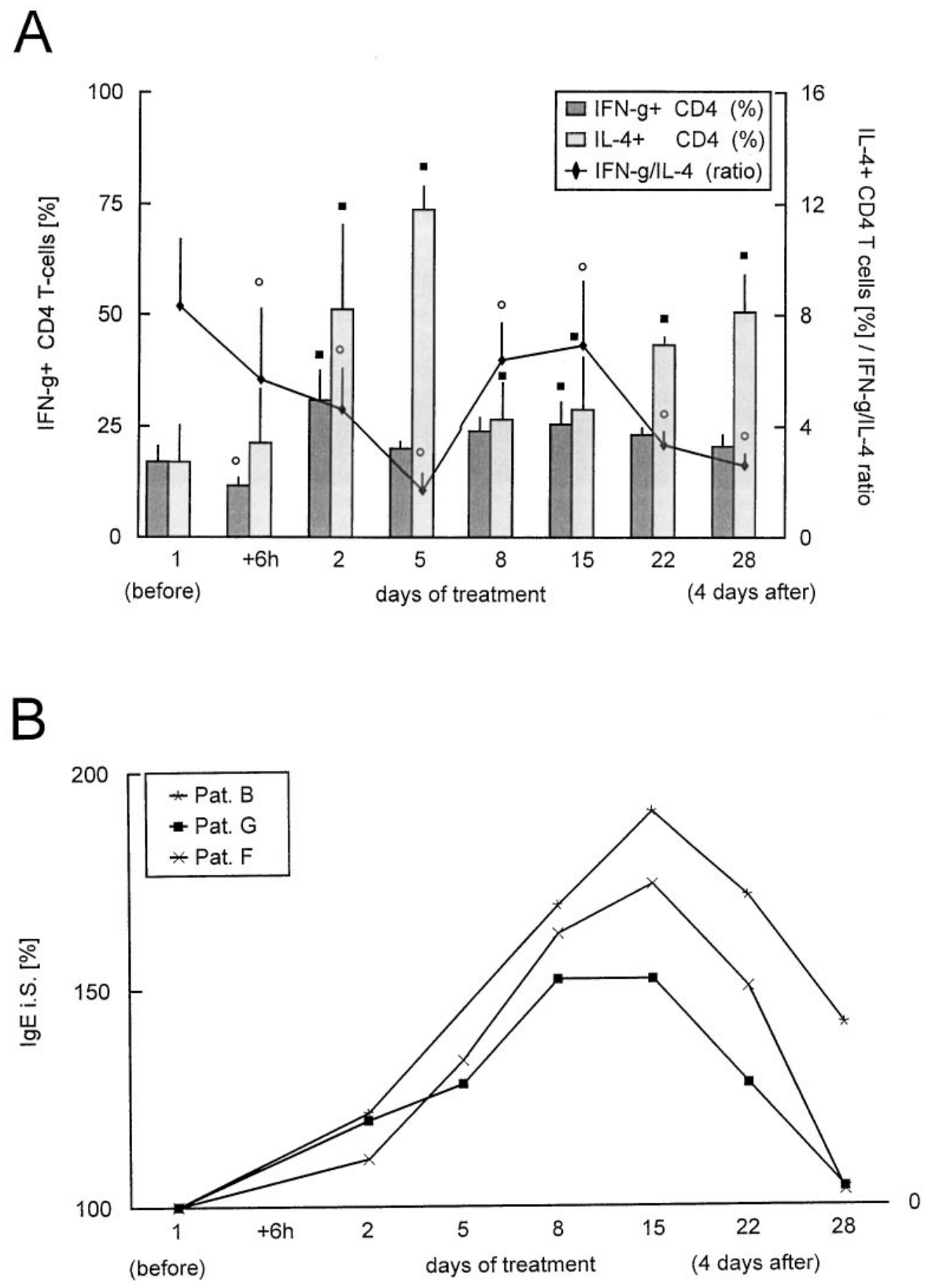

Figure 10. IL-10 therapy only initially depressed IFN- $\gamma$ secretion capacity but lastingly upregulated the proportion of IL-4 secreting $\mathrm{CD}^{+} \mathrm{T}$ cells and IgE plasma levels. $(A)$ In three psoriatic patients undergoing IL-10 therapy, the percentage of IFN- $\gamma$ and IL-4 producing CD $4^{+} \mathrm{T}$ cells was cytofluorometrically determined after $4 \mathrm{~h}$ of PMA/ionomycin stimulation of whole blood as described in Methods. For assessing the Th1/Th2 cytokine balance, the IFN- $\gamma /$ IL-4 ratio was calculated. The data of the three psoriatic patients are given as mean \pm SEM. Filled boxes, Values were higher than before IL-10 therapy for all three patients. Open circles, Values were lower than before IL-10 therapy for all three patients. $(B)$ In three psoriatic patients undergoing IL-10 therapy, the IgE serum levels were determined by ELISA. The pretreatment values were considered as $100 \%$ for each patient (Pat. B: 244 kU/liter; Pat. G: 73.4 kU/liter; Pat F: 7.6 $\mathrm{kU} / \mathrm{liter}$ ).

served in all patients, although the degree was different and no complete response was reached. This does not argue against the use of IL-10 as an antipsoriatic agent since the period of administration ( $24 \mathrm{~d}$ ) and monitoring (28 d) were comparatively short and we selected patients with severe course of psoriasis. Several well established (e.g., fumaric acid esters) (44) or experimental therapies (45) do not show significant clinical effects when used as monotherapy for such short periods. Since our data suggest that subcutaneous injection of IL-10 is safe and effective in psoriatic patients, the antipsoriatic activity of IL-10 should be further investigated in larger populations, with administration over a longer time, and with an extensive observation period. Moreover, after dose finding has been performed double-blind trials are necessary.

Based on our data, we think that the antipsoriatic activity of IL-10 results from effects on different cell populations (in- cluding T cells, antigen-presenting cells [APCs], and keratinocytes) and their interactions.

It is well established that psoriasis is a T cell-dependent immune disease $(2,5,6,8-10,21)$. The pathophysiological process is probably initiated by presentation of so far unknown "psoriasis-related antigens" by specialized cutaneous APCs $(46,47)$. IL-10 is able to suppress the APC activity of monocytes/macrophages and dendritic cells $(23,24)$. Interestingly, Mitra and colleagues demonstrated in vitro that psoriatic skinderived dendritic cell function is inhibited as well by IL-10 (47). The importance of the costimulatory component provided by APCs has been shown very recently by the therapeutic effect of CTLA4-Ig in psoriasis (45).

In our study, we demonstrated strong effects of IL-10 therapy on APCs. So, a considerable decrease of monocytic MHC class II (HLA-DR) expression was observed. We and others 


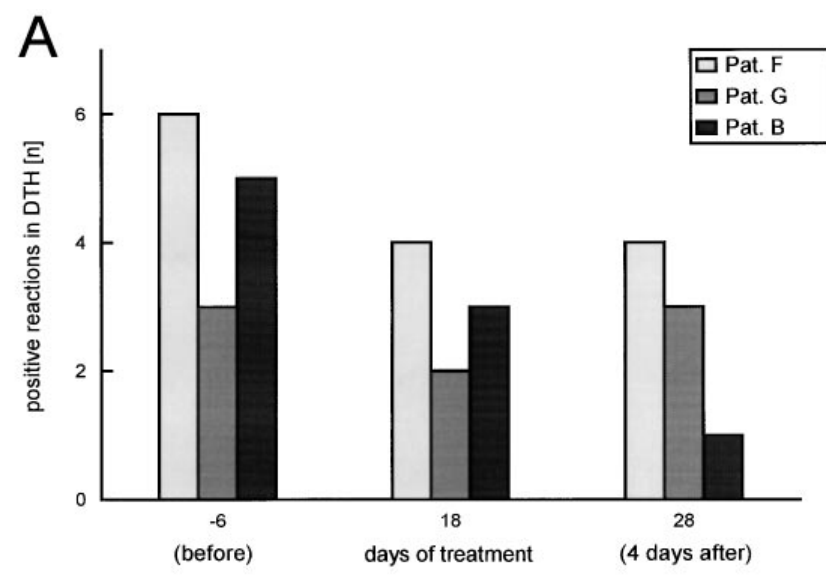

B

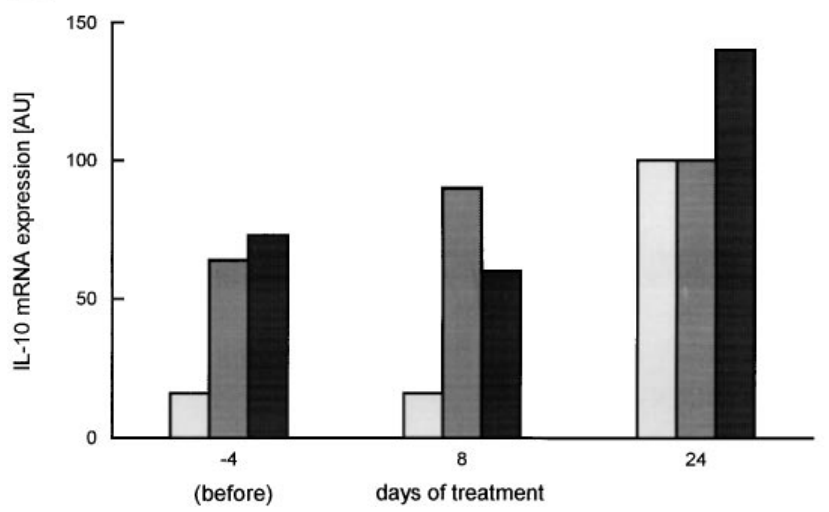

Figure 11. IL-10 therapy increased intralesional IL-10 mRNA expression and diminished DTH response to recall antigens in the nonlesional cutis. $(A)$ In three psoriatic patients undergoing IL-10 therapy, the DTH response to recall antigens was assessed using Multitest Mérieux $^{\mathrm{TM}}$ in the nonlesional cutis before (day -6), during (day 18), and $4 \mathrm{~d}$ after the end of IL-10 therapy (day 28). The number of positive antigen tests (seven antigens) for each patient is given. $(B)$ In three psoriatic patients lesional skin biopsies were obtained $4 \mathrm{~d}$ before, during (day 8), and at the end of IL-10 therapy (day 24). Intralesional IL-10 mRNA expression was determined using semiquantitative RT-PCR and is expressed in AU as described in Methods.

have shown that low monocytic HLA-DR expression indicates systemic immunodepression and is associated with a functional deactivation of these important immune cells, particularly suppression of antigen-presenting capacity, formation of reactive oxygen species, and capacity to produce proinflammatory cytokines $(31,48)$. Accordingly, we found a depression of monocytic TNF- $\alpha$ and IL-12 secretion capacity as well as decreasing plasma levels of IL-12 which is critically important for the generation of cell-mediated immunity (49).

Presentation of classical intraepidermal antigens and/or superantigens activates $\mathrm{T}$ effector cells in psoriasis $(46,50)$. In particular, type 1 cytokine producing $\mathrm{T}$ cells seem to play an important role in the pathogenesis of the disease $(4,5,50)$. Our data show that IL-10 administration influences the T cell subpopulations with regard to their ex vivo cytokine formation capacity. Although we have some evidence for counterregulation, a clear type 1/type 2 shift was found. This is the first in vivo report on this important effect of IL-10. On the one hand, the diminished response to recall antigens during and after therapy and the depressed IL-12 p40 plasma levels indicate a decreasing type 1 cytokine-mediated immune response. On the other hand, the increasing proportions of IL-4, IL-5, and IL-10 producing $\mathrm{T}$ cells as well as IgE levels in serum indicated a rising type 2 cytokine formation. Moreover, we found increasing cutaneous IL-10 mRNA expression probably reflecting the systemic shift of the cytokine pattern in the skin.

Finally, direct effects of IL-10 on keratinocytes may have contributed to the clinical response observed. So, it has been shown that IL-10 inhibits keratinocytic proinflammatory cytokine synthesis (51). It is still controversial as to whether human keratinocytes are able to produce IL-10 (52-54) and, therefore, if they are involved in the increasing cutaneous IL-10 mRNA expression demonstrated in our patients. Interestingly, it has been reported that keratinocyte-derived IL-10 mediates the UV-induced suppression of DTH reaction in mice (55).

Taken together, our data suggest safety, immunological activity, and therapeutic potency of IL-10 treatment in psoriasis, a disease where relative IL-10 deficiency seems to be of crucial importance. Administration as well as induction of IL-10 may be useful novel approaches for psoriasis treatment.

\section{Acknowledgments}

We thank Ms. Antje Haeussler, Ms. Christa Liebenthal, Ms. Christin Neuhaus, Markus Friedrich, and Holger Schmid for their excellent technical assistance.

This work was partly supported by the Deutsche Forschungsgemeinschaft (Ste 366/7-1) and Schering-Plough/Essex Pharma, Germany.

\section{References}

1. Christophers, E., and W. Sterry. 1993. Psoriasis. In Dermatology in General Medicine. T.B. Fitzpatric, A.Z. Eisen, K. Wolff, I.M. Freedberg, and K.F. Austen, editors. McGraw-Hill, New York. 489-515.

2. Valdimarsson, H., B.S. Baker, I. Johnsdottir, and L. Fry. 1986. Psoriasis: a disease of abnormal keratinocyte proliferation induced by T lymphocytes. Immunol. Today. 7:256-259.

3. Nickoloff, B.J. 1991. The cytokine network in psoriasis. Arch. Dermatol. 127:871-884.

4. Uyemura, K., M. Yamamura, D.F. Fivenson, R.L. Modlin, and B.J. Nickoloff. 1993. The cytokine network in lesional and lesion-free psoriatic skin is characterized by a T-helper type 1 cell-mediated response. J. Invest. Dermatol. 101:701-705.

5. Schlaak, J.F., M. Buslau, W. Jochum, E. Hermann, M. Girndt, H. Gallati, K.H. Meyer zum Büschenfelde, and B. Fleischer. 1994. T cells involved in psoriasis vulgaris belong to the Th 1 subset. J. Invest. Dermatol. 102:145-149.

6. Wrone-Smith, T., and B.J. Nickoloff. 1996. Dermal injection of immunocytes induces psoriasis. J. Clin. Invest. 98:1878-1887.

7. Krueger, J.G., J.F. Krane, D.M. Carter, and A.B. Gottlieb. 1990. Role of growth factors, cytokines, and their receptors in the pathogenesis of psoriasis. $J$. Invest. Dermatol. 94:135S-140S.

8. Boehncke, W.H., D. Dressel, B. Manfras, T.M. Zollner, A. Wettstein, B.O. Böhm, and W. Sterry. 1995. T-cell-receptor repertoire in chronic plaquestage psoriasis is restricted and lacks enrichment of superantigen-associated V $\beta$ regions. J. Invest. Dermatol. 104:725-728.

9. Takashima, A., and A. Morita. 1991. Genomic, phenotypic, and functional analyses of $\mathrm{T}$ cells in patients with psoriasis undergoing systemic cyclosporine A treatment. J. Invest. Dermatol. 96:376-382.

10. Jegasothy, B.V., C.D. Ackerman, S. Todo, J.J. Fung, K. Abu-Elmagd, and T.E. Starzl. 1992. Tacrolimus (FK 506): a new therapeutic agent for severe recalcitrant psoriasis. Arch. Dermatol. 128:781-785.

11. Altmeyer, P.J., U. Matthes, F. Pawlak, K. Hoffmann, P.J. Frosch, P. Ruppert, S.W. Wassilew, T. Horn, H.W. Kreysel, G. Lutz, et al. 1994. Antipsoriatic effect of fumaric acid derivatives. Results of a multicenter double-blind study in 100 patients. J. Am. Acad. Dermatol. 30:977-981.

12. De Jong, R., A.C. Bezemer, T.P.L. Zomerdijk, T. van de Pouw-Kraan, T.H.M. Ottenhoff, and P.H. Nibbering. 1996. Selective stimulation of T helper 2 
cytokine responses by the anti-psoriasis agent monomethylfumarate. Eur. J. Immunol. 26:2067-2074.

13. Asadullah, K., H. Schmid, M. Friedrich, F. Randow, H.D. Volk, W. Sterry, and W.D. Döcke. 1997. Influence of monomethylfumarate on monocytic cytokine formation: explanation for adverse and therapeutic effects in psoriasis? Arch. Dermatol. Res. 289:623-630.

14. Romagnani, S. 1995. Biology of human Th1 and Th2 cells. J. Clin. Immunol. 15:121-129.

15. Ohta, Y., I. Katayama, T. Funato, H. Yokozeki, S. Nishiyama, T. Hirano, T. Kishimoto, and K. Nishioka. 1991. In situ expression of messenger RNA of interleukin-1 and interleukin-6 in psoriasis: interleukin-6 involved in formation of psoriatic lesions. Arch. Dermatol. Res. 283:351-356.

16. Lemster, B.H., P.B. Carroll, H.R. Rilo, N. Johnson, A. Nikaein, and A.W. Thomson. 1995. IL-8/IL-8 receptor expression in psoriasis and the response to systemic tacrolimus (FK506) therapy. Clin. Exp. Immunol. 99:148-154.

17. Ettehadi, P., M.W. Greaves, D. Wallach, D. Aderka, and R.D. Camp. 1994. Elevated tumour necrosis factor-alpha (TNF-alpha) biological activity in psoriatic skin lesions. Clin. Exp. Immunol. 96:146-151.

18. Kristensen, M., B. Deleuran, D.J. Eedy, M. Feldmann, S.M. Breathnach, and F.M. Brennan. 1992. Distribution of interleukin 1 receptor antagonist protein (IRAP), interleukin 1 receptor, and interleukin 1 alpha in normal and psoriatic skin. Decreased expression of IRAP in psoriatic lesional epidermis. Br. J. Dermatol. 127:305-311.

19. Jenkins, J.K., M. Malyak, and W.P. Arend. 1994. The effects of interleukin-10 on interleukin-1 receptor antagonist and interleukin-1 beta production in human monocytes and neutrophils. Lymphokine Cytokine Res. 13:47-54.

20. Olaniran, A.K., B.S. Baker, D.G. Paige, J.J. Garioch, A.V. Powles, and L. Fry. 1996. Cytokine expression in psoriatic skin lesions during PUVA therapy. Arch. Dermatol. Res. 288:421-425.

21. Jeffes, E.W.B. III, G.C. Lee, S. Said, M. Sabahi, J.L. McCullough, R. Herrod, C.P. Alzona, K.G. Linden, D. Soundararajan, S. Edwards, and G.D. Weinstein. 1995. Elevated numbers of proliferating mononuclear cells in the peripheral blood of psoriatic patients correlate with disease severity. J. Invest. Dermatol. 105:733-738.

22. D'Andrea, A., M. Aste-Amezaga, N.M. Valiante, X. Ma, M. Kubin, and G. Trinchieri. 1993. Interleukin 10 (IL-10) inhibits human lymphocyte interferon gamma-production by suppressing natural killer cell stimulatory factor/ IL-12 synthesis in accessory cells. J. Exp. Med. 178:1041-1048.

23. De Waal Malefyt, R., J. Abrams, B. Bennett, C.G. Figdor, and J.E. de Vries. 1991. Interleukin 10 (IL-10) inhibits cytokine synthesis by human monocytes: an autoregulatory role of IL-10 produced by monocytes. J. Exp. Med. 174:1209-1220.

24. Fiorentino, D.F., A. Zlotnik, T.R. Mosmann, M. Howard, and A. O'Garra. 1991. IL-10 inhibits cytokine production by activated macrophages. $J$. Immunol. 147:3815-3822.

25. Chernoff, A.E., E.V. Granowitz, L. Shapiro, E. Vannier, G. Lonnemann, J.B. Angel, J.S. Kennedy, A.R. Rabson, S.M. Wolff, and C.A. Dinarello. 1995. A randomized, controlled trial of IL-10 in humans. Inhibition of inflammatory cytokine production and immune responses. J. Immunol. 154:54925499.

26. Van Deventer, S., C.O. Elson, and R.N. Fedorak for the Crohn's disease study group. 1997. Multiple dose of intravenous interleukin-10 in steroid refractory Crohn's disease. Gastroenterology. 113:383-389.

27. Fredriksson, T., and U. Pettersson. 1978. Severe psoriasis: oral therapy with a new retinoid. Dermatologica. 157:238-244.

28. Hoffmann, K., T. Dirschka, H. Schwarze, S. el-Gammal, U. Matthes, A. Hoffmann, and P. Altmeyer. 1995. 20 Mhz sonography, colorimetry, and image analysis in the evaluation of psoriasis vulgaris. J. Dermatol. Sci. 9:103-110.

29. Platzer, C., S. Ode Hakim, P. Reinke, W.D. Döcke, R. Ewert, and H.D. Volk. 1994. Quantitative PCR analysis of cytokine transcription patterns in peripheral mononuclear cells after anti-CD3 rejection therapy using two novel multispecific competitor fragments. Transplantation. 58:264-268.

30. Asadullah, K., W.D. Döcke, A. Haeussler, W. Sterry, and H.D. Volk. 1996. Progression of mycosis fungoides is associated with increasing cutaneous expression of IL-10 mRNA. J. Invest. Dermatol. 107:833-837.

31. Döcke, W.D., F. Randow, U. Syrbe, D. Krausch, K. Asadullah, P. Reinke, H.D. Volk, and W. Kox. 1997. Monocyte deactivation in septic patients: restitution by IFN- $\gamma$ treatment. Nat. Med. 3:678-681.

32. Ohmen, J.D., J.M. Hanifin, B.J. Nickoloff, T.H. Rea, R. Wyzykowski, J. Kim, D. Jullien, T. McHugh, A.S. Nassif, S.C. Chan, and R.L. Modlin. 1995. Overexpression of IL-10 in atopic dermatitis. J. Immunol. 154:1956-1963.

33. Nickoloff, B.J., D.P. Fivenson, S.L. Kunkel, R.M. Strieter, and L.A. Turka. 1994. Keratinocyte interleukin-10 expression is upregulated in tape- stripped skin, poison ivy dermatitis, and Sezary syndrome, but not in psoriatic plaques. Clin. Immunol. Immunopathol. 73:63-68.

34. Mussi, A., C. Bonifati, M. Carducci, M. Viola, R. Tomaselli, G. Sacerdoti, M. Fazio, and F. Ameglio. 1994. IL-10 levels are decreased in psoriatic lesional skin as compared with the psoriatic lesion-free and normal skin suction blister fluids. J. Biol. Regul. Homeost. Agents. 8:117-120.

35. Enk, C.D., D. Sredni, A. Blauvelt, and S.I. Katz. 1995. Induction of IL10 gene expression in human keratinocytes by UVB exposure in vivo and in vitro. J. Immunol. 154:4851-4856.

36. Platzer, C., C. Meisel, K. Vogt, M. Platzer, and H.D. Volk. 1995. Upregulation of monocytic IL-10 by tumor necrosis factor-alpha and cAMP elevating drugs. Int. Immunol. 7:517-523.

37. Gilhar, A., N. Grossman, S. Kahanovicz, H. Reuveni, S. Cohen, and A. Eitan. 1996. Antiproliferative effect of pentoxifylline on psoriatic and normal epidermis. Acta. Derm. Venereol. (Stockh.). 76:437-441.

38. Das, N.S., T.N. Chowdary, C. Sobhanadri, and K.V. Rao. 1978. The effect of topical isoprenaline on psoriatic skin. Br. J. Dermatol. 99:197-200.

39. Abel, E.A., L.M. DiCicco, E.K. Orenberg, J.E. Fraki, and E.M. Farber. 1986. Drugs in exacerbation of psoriasis. J. Am. Acad. Dermatol. 15:1007-1022. 40. Wölfer, L.U., S. Goerdt, K. Schröder, C.C. Zouboulis, and C.E. Orfanos. 1996. Interferon-alpha induced psoriasis. Hautarzt. 47:124-128.

41. Ockenfels, H.M., S.N. Wagner, C. Keim-Maas, R. Funk, G. Nussbaum, and M. Goos. 1996. Lithium and psoriasis: cytokine modulation of cultured lymphocytes and psoriatic keratinocytes by lithium. Arch. Dermatol. Res. 288: 173-178.

42. Wegmann, T.G., H. Lin, L. Guilbert, and T.R. Mosmann. 1993. Bidirectional cytokine interactions in the maternal-fetal relationship: is successful pregnancy a Th2 phenomenon? Immunol. Today. 14:353-356.

43. Boyd, A.S., L.F. Morris, C.M. Phillips, and M.A. Menter. 1996. Psoriasis and pregnancy: hormone and immune system interaction. Int. J. Dermatol. 35: 169-172.

44. Thio, H.B., J.G. van der Schroeff, W.M. Nugteren-Huying, and B.J. Vermeer. 1995. Long-term systemic therapy with dimethylfumarate and monoethylfumarate (Fumaderm ${ }^{\mathrm{TM}}$ ) in psoriasis. Journal of the European Academy of Dermatology and Venereology. 4:35-40.

45. Krueger, J.G., E. Hayes, M. Brown, S. Kang, M.G. Lebwohl, C.A Guzzo, B.V. Jegasothy, M.T. Goldfarb, D.J. Hecker, R.M. Mann, and J.R. Abrams. 1997. Blockade of T-cell costimulation with CTLA4Ig reverses pathologic inflammation and keratinocyte activation in psoriasis. J. Invest. Dermatol. 108:555. (Abstr.)

46. Weinstein, G.D. 1996. Can immunomodulatory molecules work topically for psoriasis? J. Invest. Dermatol. 106:589.

47. Mitra, R.S., T.A. Judge, F.O. Nestle, L.A. Turka, and B.J. Nickoloff 1995. Psoriatic skin-derived dendritic cell function is inhibited by exogenous IL10. Differential modulation of B7-1 (CD80) and B7-2 (CD86) expression. J. Immunol. 154:2668-2677.

48. Volk, H.D., P. Reinke, D. Krausch, H. Zuckermann, K. Asadullah, J.M. Müller, W.D. Döcke, and W.J. Kox. 1996. Monocyte deactivation: rationale for a new therapeutic strategy in sepsis. Intens. Care. Med. 22:S474-S481.

49. Germann, T., and E. Rude-E. 1995. Interleukin-12. Int. Arch. Allergy Immunol. 108:103-112.

50. Norris, D.A., J.B. Traves, and D.Y.M. Leung. 1997. Lymphocyte activation in the pathogenesis of psoriasis. J. Invest. Dermatol. 109:1-4.

51. Becherel, P.A., L. LeGoff, S. Ktorza, F. Ouaaz, J.M. Mencia Huerta, B. Dugas, P. Debre, M.D. Mossalayi, and M. Arock. 1995. Interleukin-10 inhibits IgE-mediated nitric oxide synthase induction and cytokine synthesis in normal human keratinocytes. Eur. J. Immunol. 25:2992-2995.

52. Teunissen, M.B.M., C.W. Koomen, J. Jansen, R. de Waal Malefyt, E. Schmitt, R.M. Van den Wijngaard, P.K. Das, and J.D. Bos. 1997. In contrast to their murine counterparts, normal human keratinocytes and human epidermoid cell lines A431 and HaCaT fail to express IL-10 mRNA and protein. Clin. Exp. Immunol. 107:213-223.

53. Kang, K., C. Hammerberg, L. Meunier, and K.D. Cooper. 1994. $\mathrm{CD} 11 \mathrm{~b}+$ macrophages that infiltrate human epidermis after in vivo ultraviolet exposure potently produce IL-10 and represent the major secretory source of epidermal IL-10 protein. J. Immunol. 153:5256-5264.

54. Enk, C.D., D. Sredni, A. Blauvelt, and S. Katz. 1995. Induction of IL-10 gene expression in human keratinocytes by UVB exposure in vivo and in vitro. J. Immunol. 154:4851-4856.

55. Rivas, J.M., and S.E. Ullrich. 1992. Systemic suppression of delayedtype hypersensitivity by supernatants from UV-irradiated keratinocytes. An essential role for keratinocyte-derived IL-10. J. Immunol. 149:3865-3871. 